\title{
VALIDATION OF LINKED SIMULATION FOR FIRE-EXPOSED CONCRETE STRUCTURES
}

\author{
Stanislav ŠulC ${ }^{a, *}$, Vít ŠmilaueR ${ }^{a}$, František $\mathrm{WALD}^{b}$ \\ ${ }^{a}$ Department of Mechanics, Faculty of Civil Engineering, CTU in Prague, Thakurova 7, 166 29 Prague 6, Czech \\ Republic \\ ${ }^{b}$ Department of Steel and Timber Structures, Faculty of Civil Engineering, CTU in Prague, Thakurova 7, 16629 \\ Prague 6, Czech Republic \\ * corresponding author: stanislav.sulc@fsv.cvut.cz
}

\begin{abstract}
This article presents linked computational approach for fire simulation and its effects on structure using adiabatic surface temperature. The simulation solves a weakly-linked problem, consisting of computational fluid dynamics (CFD), heat transport and mechanical model. The temperature field from the CFD creates Cauchy and radiative boundary conditions for the thermal model. The temperature field from an element is passed further to the mechanical model, which induces thermal strain and modifies material parameters. This article also brings a validation of the linked simulation, based on experiment with a concrete block exposed to fire in a furnace. The material model uses standard material properties given in Eurocode 2 - EN 1992-1-2.
\end{abstract}

KEYwords: Thermo-mechanical model, virtual furnace, computational fluid dynamics, multiphysics, fire resistance.

\section{INTRODUCTION}

Structural fire assessment creates essential part in design and maintenance of steel, concrete or timber structures. Expensive empirical tests carried out in furnaces with gas burners present traditional approach. This article describes a software tool for prediction of the thermo-mechanical response of a structure exposed to fire. It extends our previously published concept 11.

We created a python library, which interconnects codes solving the particular physical phenomena (CFD, thermal and mechanical task).

The issue of CFD is solved with the Fire Dynamics Simulator software (FDS) [2], developed at NIST. We created a standardized API for governing the computation and exporting the data, which brought some changes in the structure of the code. This computation provides the temperature fields for the following thermal analysis. Our FDS computations have already been validated against experiment by Cábová et al. 3].

The thermo-mechanical analysis of the element takes place in OOFEM [4] software. The thermal analysis uses Adiabatic Surface Temperature (AST) field from FDS, which defines both Cauchy and radiative boundary conditions on the element's surfaces. AST is further explained in Sec. 1.1. Then, the solution of the thermal analysis passes resulting temperature field to the mechanical analysis, which induces thermal strain and modifies the material parameters as yield strength and elastic modulus.

Interfacing FDS and OOFEM is realized using MuPIF [5] Python library, which provides useful tools such as exporting data to VTU format, parallel computations and advanced handling with data fields and meshes. Both the FDS Fortran and OOFEM C++ codes were compiled as shared libraries and imported into the Python code. The top-level steering script controls execution of both codes, data synchronization etc. Fig. 1 shows the data flow using the MODA diagram [6].

\subsection{Adiabatic surface temperature}

Convection and radiation present dominant boundary conditions for a structure exposed to fire. This could be facilitated by AST, a concept brought by Wickström [7]. The total heat flux to the surface of an element reads

$$
q_{\mathrm{tot}}=q_{\mathrm{con}}+q_{\mathrm{rad}}
$$

Convection and radiation terms are further expressed as

$$
\begin{gathered}
q_{\mathrm{con}}=h\left(T_{\mathrm{g}, \mathrm{CFD}}-T_{\mathrm{TM}}\right) \\
q_{\mathrm{rad}}=\varepsilon\left(R_{\mathrm{inc}, \mathrm{CFD}}-\sigma T_{\mathrm{TM}}^{4}\right)
\end{gathered}
$$

where $h$ is the heat transfer coefficient, $\sigma$ is the StefanBoltzmann constant, $\varepsilon$ is the emissivity of the exposed surface, $T_{\mathrm{TM}}$ is the temperature of a surface in the thermal model in OOFEM, $T_{\mathrm{g}, \mathrm{CFD}}$ is the gas temperature in the CFD model in FDS and $R_{\text {inc,CFD }}$ is the so called incidental radiation. It is the sum of all radiative sources in FDS

$$
R_{\mathrm{inc}, \mathrm{CFD}}=\sum \varepsilon_{i} F_{i} \sigma T_{\mathrm{inc}, i}^{4}
$$

where $T_{i n c, i}$ stands for the temperature of each flame or hot surface, $\varepsilon_{i}$ is its emissivity and $F_{i}$ is the view factor between the source and the oriented surface 


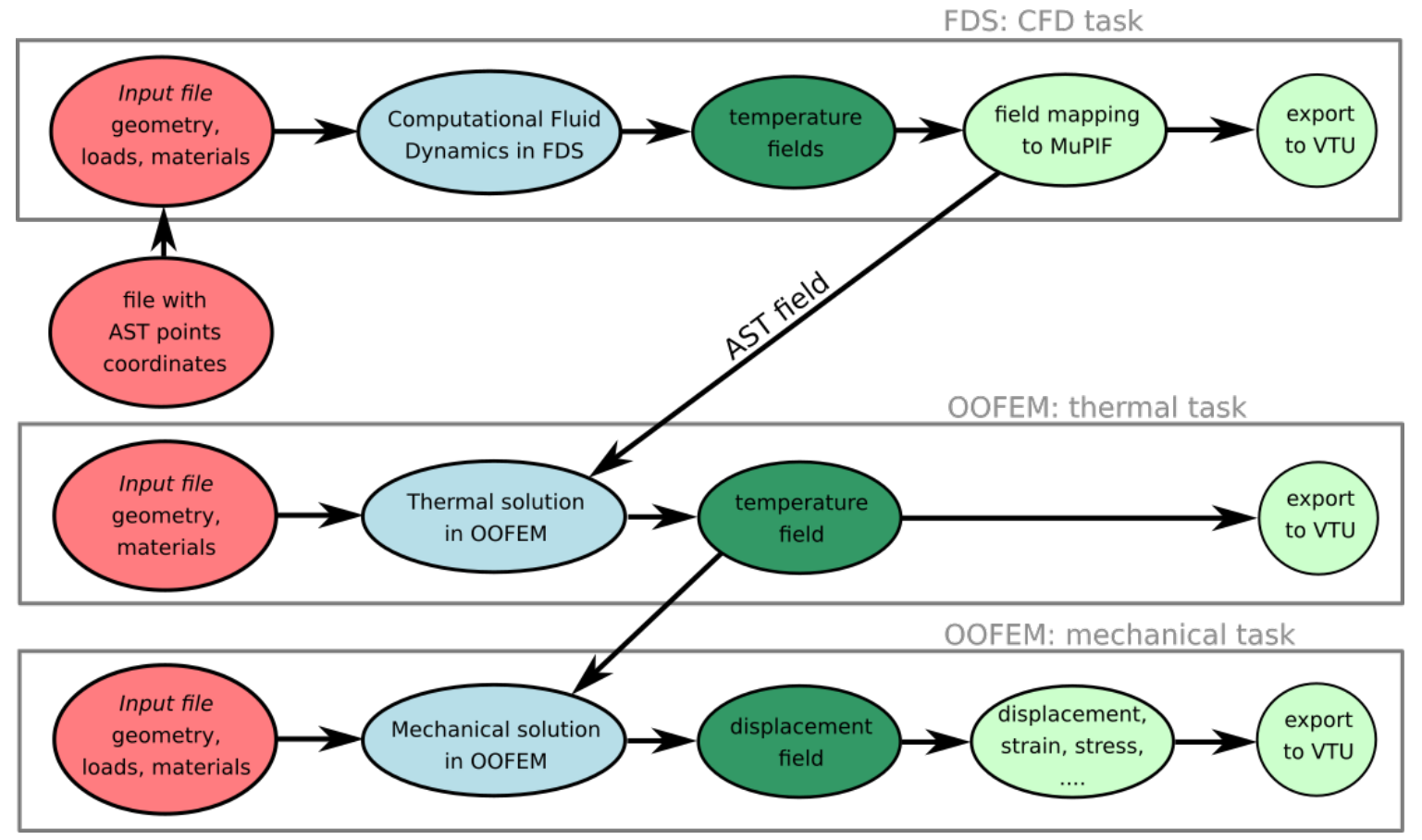

FiguRE 1. Data workflow diagram.

of the structure. FDS can automatically obtain the value of $R_{\text {inc,CFD. }}$.

FDS software computes AST ( $\left.\mathrm{T}_{\mathrm{AST}}\right)$. It corresponds to the temperature of a perfect insulator's surface with zero conduction, see Fig. 2. The heat flux to this surface is set to zero by the following equation

$$
0=\varepsilon\left(R_{\mathrm{inc}, \mathrm{CFD}}-\sigma T_{\mathrm{AST}}^{4}\right)+h\left(T_{\mathrm{g}, \mathrm{CFD}}-T_{\mathrm{AST}}\right)
$$

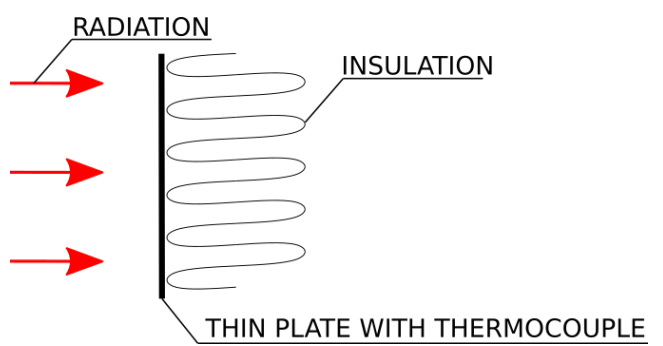

Figure 2. Plate thermometer for AST measurement.

The total heat flux from the fire model to the thermal model reads as

$$
q_{\mathrm{tot}}=\varepsilon\left(R_{\mathrm{inc}, \mathrm{CFD}}-\sigma T_{\mathrm{TM}}^{4}\right)+h\left(T_{\mathrm{g}, \mathrm{CFD}}-T_{\mathrm{TM}}\right)
$$

and subtracting Eqs. 5 and 6 leads to

$$
q_{\mathrm{tot}}=\varepsilon \sigma\left(T_{\mathrm{AST}}^{4}-T_{T M}^{4}\right)+h\left(T_{\mathrm{AST}}-T_{T M}\right)
$$

According to Eq. 7) passing a single field $T_{\mathrm{AST}}$ suffices to link CFD with the thermo-mechanical task.

\section{VALIDATION - EXPERIMENT WITH A CONCRETE BLOCK}

We present a validation based on a concrete block $(0.35 \mathrm{~m} \times 0.15 \times 0.2 \mathrm{~m})$ exposed to fire in a horizontal furnace, placed below the its ceiling. The experiment also involved concrete column elements, which were a part of another research project. Concrete class C30/37 with cement's amount of $370 \mathrm{~kg} / \mathrm{m}^{3}$ constituted the block. In order to avoid spalling of the surface, the concrete contained $1.5 \mathrm{~kg} / \mathrm{m}^{3}$ of PP fibers. Indeed, no spalling had occurred as evident from Fig. 3 .

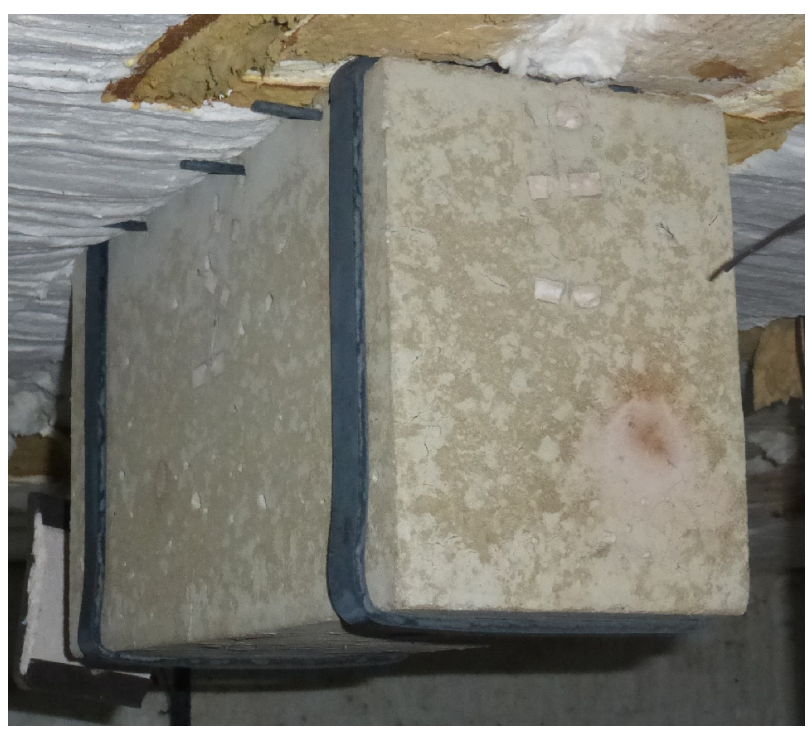

Figure 3. Concrete block after the fire exposure.

The furnace dimensions are: length $=4.00 \mathrm{~m}$, width $=2.95 \mathrm{~m}$ and height $=2.57 \mathrm{~m}$. See the horizontal and vertical sections in Figs. 5 and 6 The experiment was realized in the fire laboratory of PAVUS a.s. The furnace was heated by 8 natural gas burners. Flue gas exhaust system was performed using a frequency fan 
placed in a conduit which was connected to the opening $(500 \mathrm{~mm} \times 800 \mathrm{~mm})$ in the floor of the furnace. the temperature in the furnace followed the standard temperature curve 8

$$
T(t)=345 \cdot \log \left(\frac{2}{15} t+1\right)+20,
$$

where $t$ is in seconds and $T$ in degree Celsius. The curve is displayed in Fig. 4 with bounds $\pm 100^{\circ} \mathrm{C}$ according to recommendation [9]. Heat power of gas

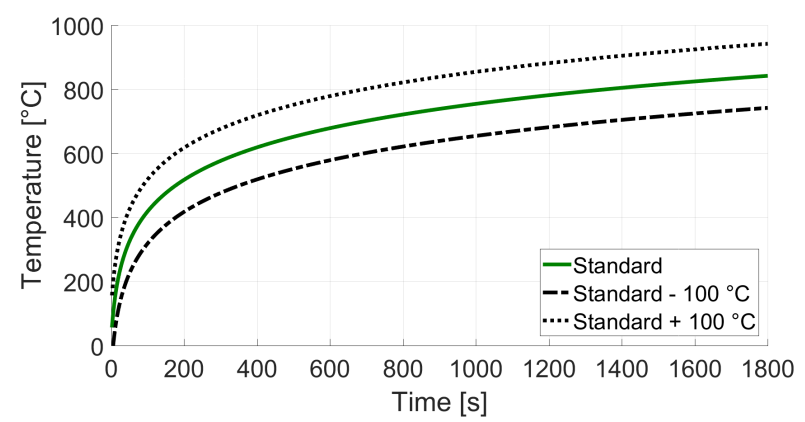

FiguRE 4. Standard temperature curve with tolerances for fire resistance testing.

burners followed the curve from Fig. 7 with the maximum output of $258 \mathrm{~kW}$. FDS used this curve for explicit control of the burners. The experiment lasted 120 minutes and the initial temperature of the whole furnace was $10^{\circ} \mathrm{C}$.

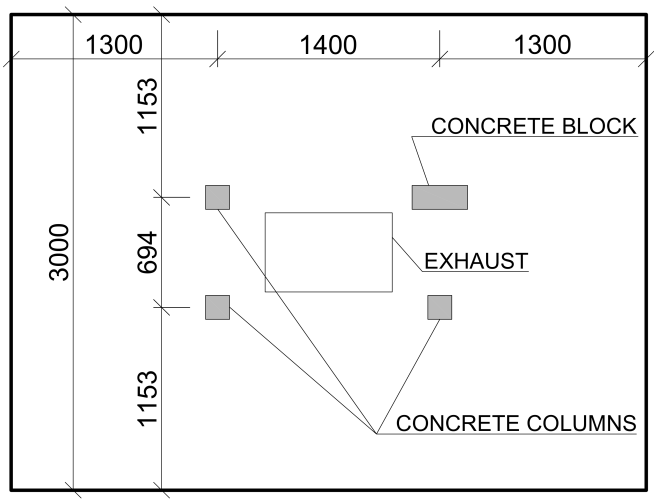

FiguRE 5. Horizontal section of the furnace.

\subsection{Simulation}

The FDS task used global mesh consisting of $36 \times$ $36 \times 24$ elements, see Fig. 9 The FDS simulation took 72 hours on $4 \mathrm{CPU}$ cores.

Regular mesh in OOFEM contained $14 \times 6 \times 10$ quadratic brick elements, see Fig. 10 . The adiabatic surface temperature was exported from points around the beam from FDS in periods of $2 s$, which is the computational step length in OOFEM.

We computed the thermal response for the validation purpose and the mechanical response to show the prediction of the mechanical behavior.

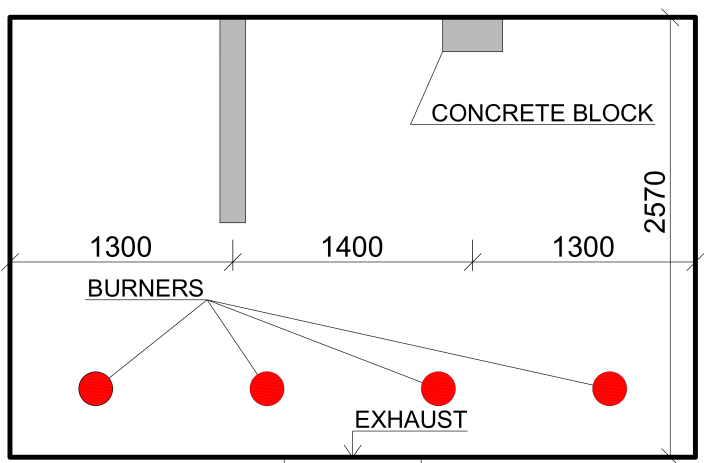

Figure 6. Vertical section of the furnace.

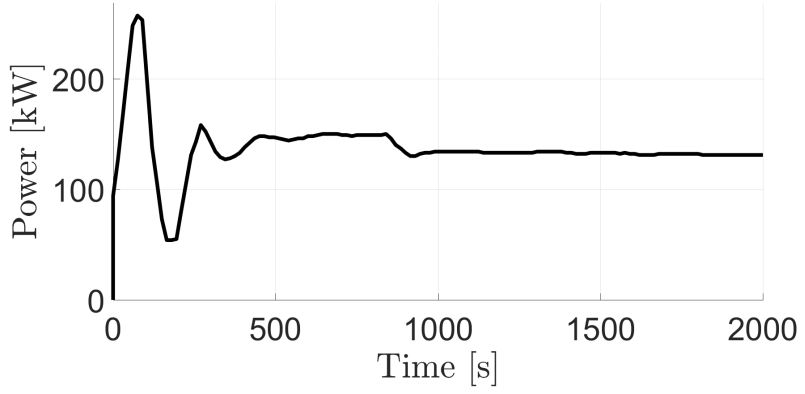

Figure 7 . Total power of gas burners.

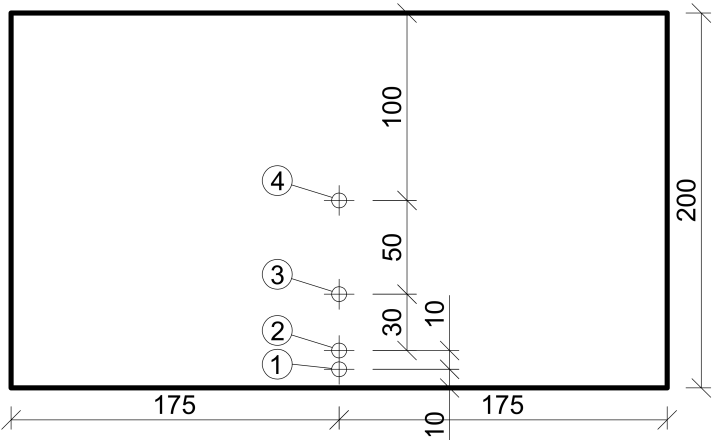

FiguRE 8. Cross-section of the concrete block with positions of the thermal sensors.

We used standard thermal material properties from Eurocode 2. Fig. 11 presents thermal conductivity and Fig. 12 presents thermal capacity of concrete.

The mechanical material properties are: Young's modulus $\mathrm{E}=30 \mathrm{GPa}$, density $\mathrm{D}=2400 \mathrm{Kgm}^{-3}, \nu=0.25$, $\alpha=12 \times 10^{-6} \mathrm{~K}^{-1}$, tensile strength is $2.1 \mathrm{MPa}$ and fracture energy is $250 \mathrm{Jm}^{-2}$.

The emissivity of concrete surface was set to 0.85 and the heat transfer coefficient was set to zero. It has almost no impact on the the results, see more in Sec. 2.3.

\subsection{Results}

Visualization of temperature field provides Fig. 13 at the time of $7200 \mathrm{~s}$. The mechanical task computes corresponding stresses; an example of $\sigma_{x x}$ field from the isotropic damage model is presented in Fig. 14 Corresponding scalar damage variable field in shown 

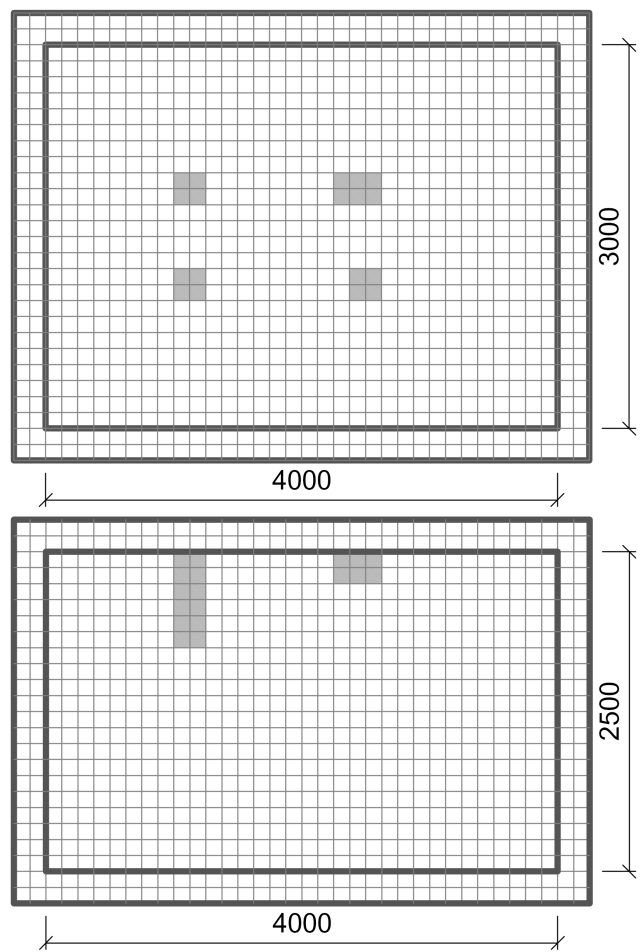

Figure 9. Meshing in the FDS model, horizontal and vertical cut through the block.

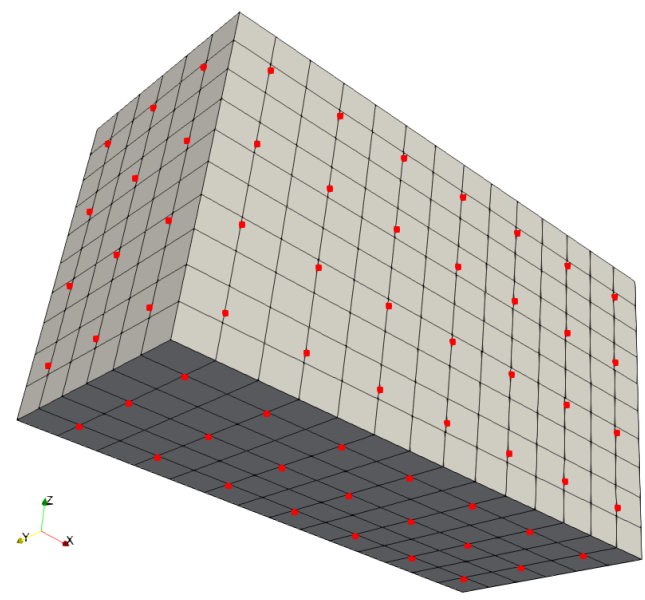

Figure 10. OOFEM mesh with AST points.

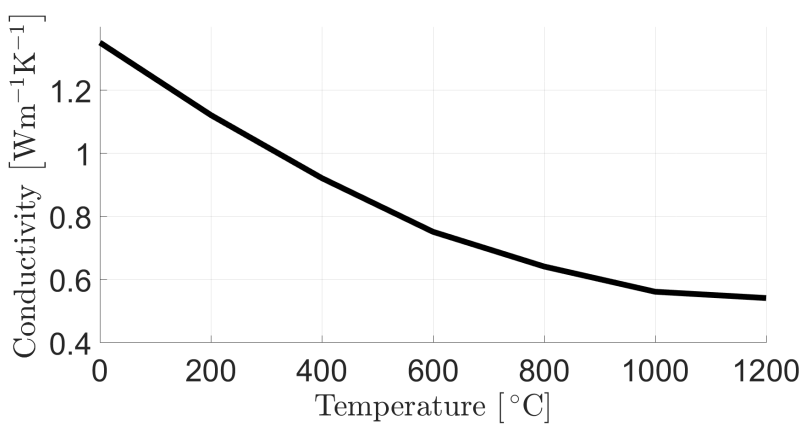

Figure 11. Thermal conductivity of concrete.

in Fig. 15. while Fig. 16 presents crack width with the maximum value of $4.8 \times 10^{-4} \mathrm{~m}$. Unfortunately, the crack width remained without validation.

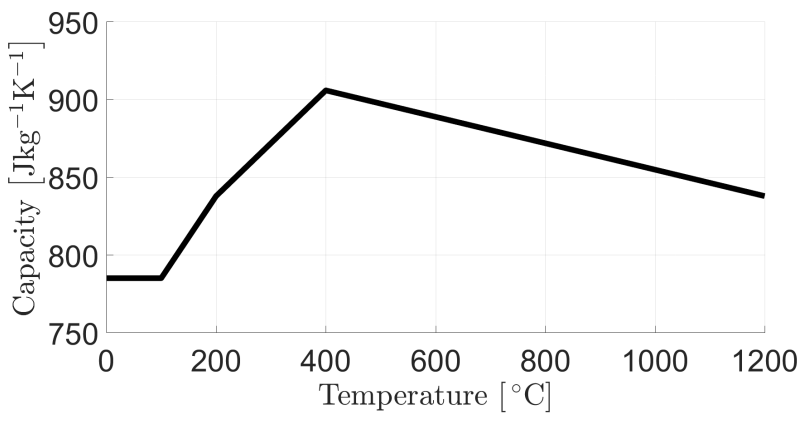

FiguRE 12. Thermal capacity of concrete.

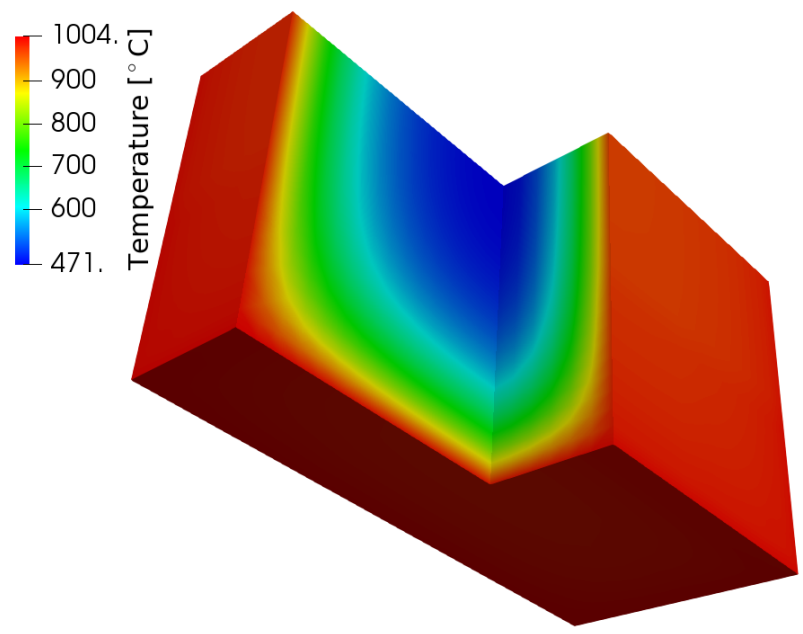

Figure 13. Temperature at time $=7200 \mathrm{~s}$.

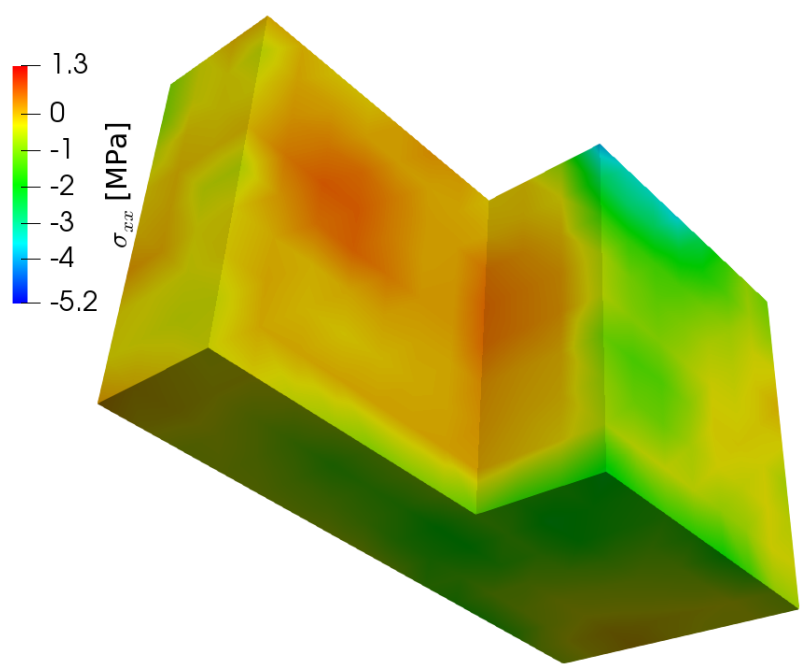

Figure 14 . Stress $\sigma_{x}$ at time $=7200 \mathrm{~s}$.

The temperatures inside the concrete block were measured in a section, which goes through the center of the block. Positions of the sensors are displayed in Fig. 8. The results in Figs. 17, 18, 19 and 20 present very satisfying match of the experimental data with the computed temperatures. We have also analyzed the influence of the emissivity and heat transfer coefficient on the results, which is negligible. For this task, the material parameters are significantly dominant. 


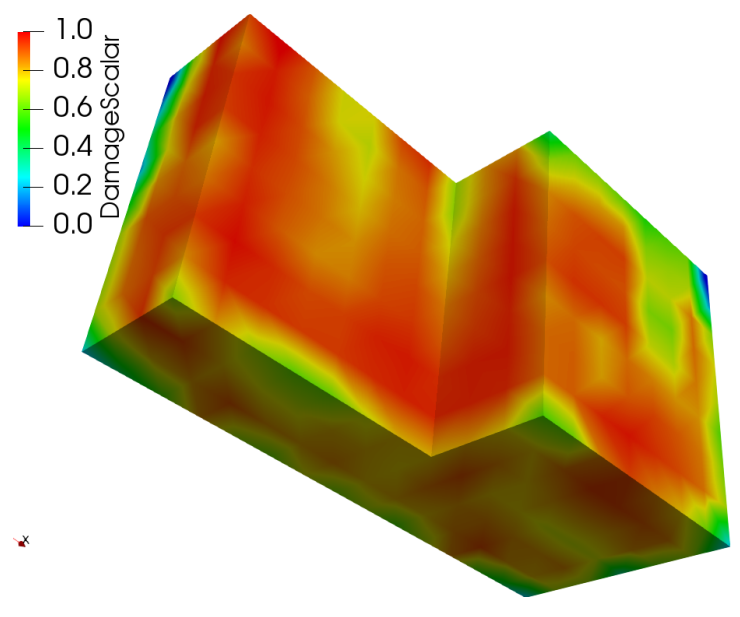

Figure 15. Damage scalar parameter at time $=7200 \mathrm{~s}$.

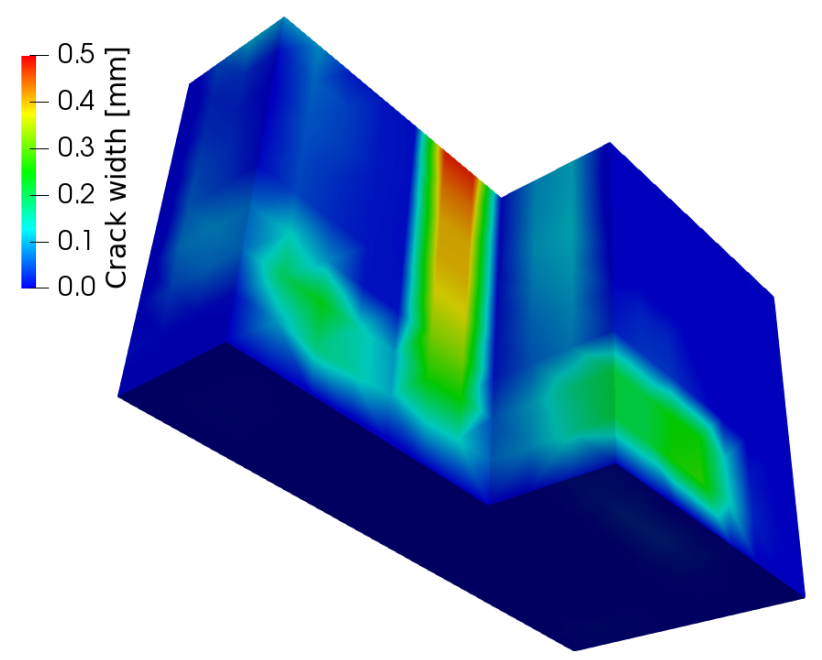

Figure 16. Crack width at time $=7200 \mathrm{~s}$.

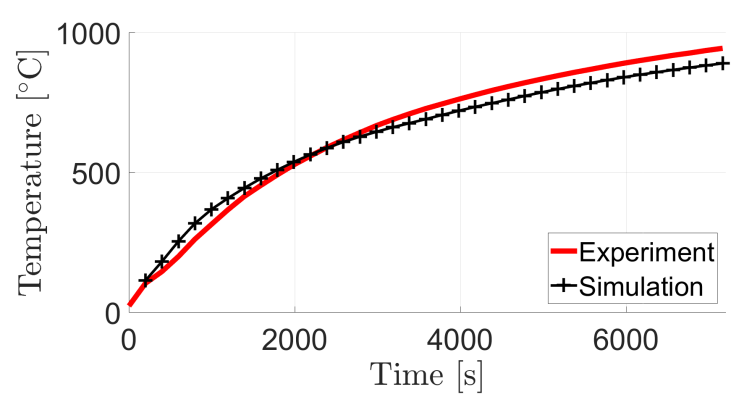

Figure 17. Temperature in \#1.

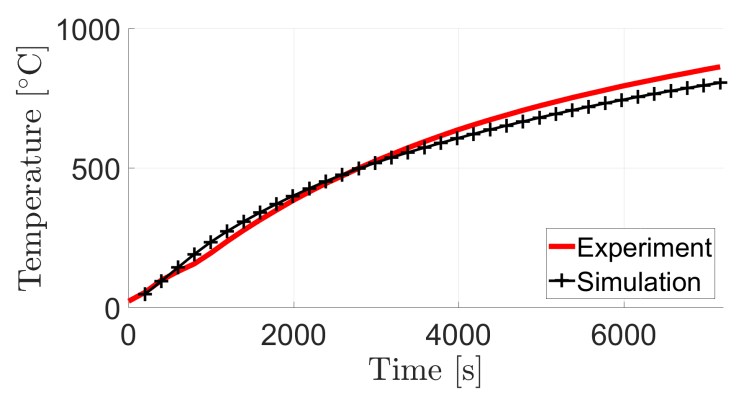

Figure 18. Temperature in \#2.

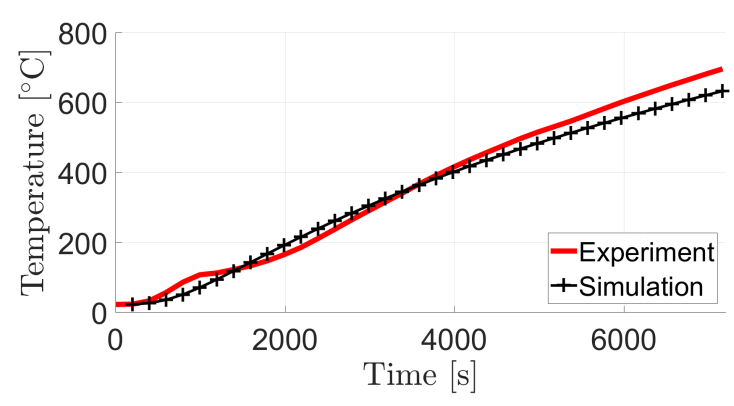

Figure 19. Temperature in \#3.

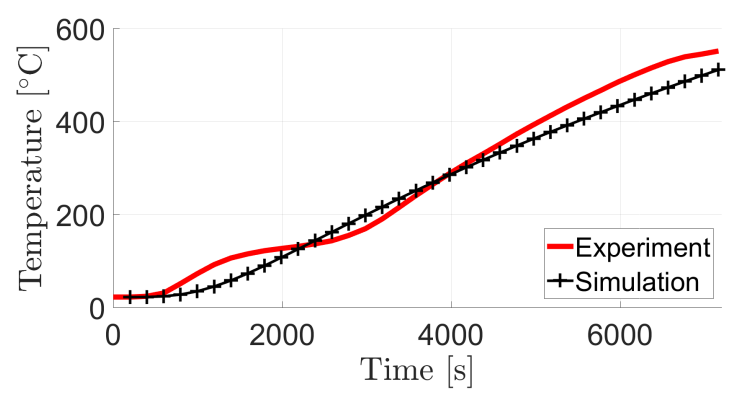

Figure 20. Temperature in \#4.

\subsection{SENSITIVITy TO HEAT TRANSFER COEFFICIENT AND EMISSIVITY}

We have checked the sensitivity of the results to setting of the heat transfer coefficient end the emissivity coefficient. Fig. 21 displays the dependency on emissivity and Fig. 22 displays the dependency on heat transfer coefficient. Both these graphs show that this

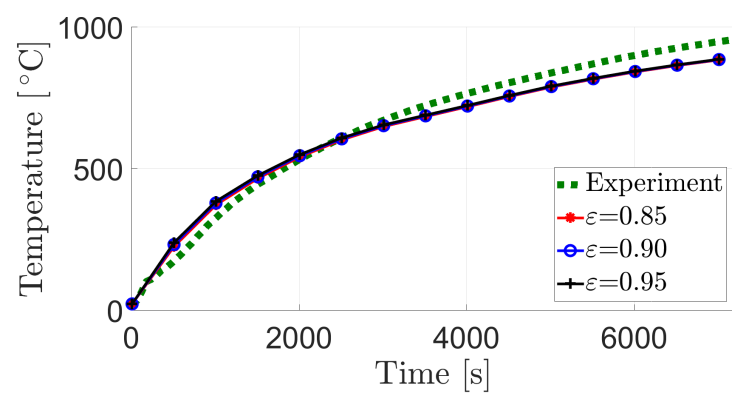

Figure 21. Temperatures in \#1 for several values of the emissivity coefficient $\varepsilon$ with no convection.

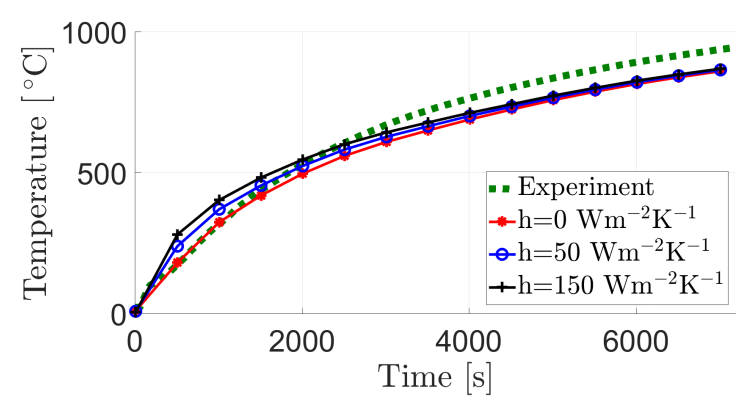

Figure 22. Temperatures in \#1 for several values of the heat transfer coefficient $h$ with $\varepsilon=0.95$. 
setting of the simulation makes almost no difference in the results and justifies the values we used for the validation.

\section{Conclusions}

This article presents new software tool and its general idea, which is interconnecting of existing softwares and using them to solve complex multi-physical problems. The softwares FDS and OOFEM were glued together with a Python library based on Python tool MuPIF.

The validation based on experiment with a concrete block exposed to fire in a furnace confirms relevancy and good accuracy of the developed software tool's computations.

\section{ACKNOWLEDGEMENTS}

We gratefully acknowledge the financial support from Czech Technical University in Prague (grant SGS18/037/OHK1/1T/11) and Czech Science Foundation (grant 16-18448S "Coupled model of structural standard fire test").

\section{REFERENCES}

[1] S. Šulc, V. Šmilauer, F. Wald. Presentation and paper "Coupled Simulation for Fire-Exposed Structures using CFD and Thermo-Mechanical Models" at NMM2017, Prague, Czech Republic, 2017.
[2] K. McGrattan, S. Hostikka, R. McDermott, et al. Fire Dynamics Simulator User's Guide. Nist special publication 1019, sixth edition, National Institute of Standards and Technology, 2017. DOI:10.6028/NIST.SP.1019

[3] K. Cábová, N. Lišková, P. Novotná, et al. presentation and paper "Modelling of Standard Fire Test" at Engineering Mechanics 2017, 15th - 18th of May 2017, Svratka, Czech Republic, 2017.

[4] B. Patzák. OOFEM - an object-oriented simulation tool for advanced modeling of materials and structures. Acta Polytechnica 52(6):59-66, 2012.

[5] B. Patzák, D. Rypl, J. Kruis. MUPIF - A distributed multi-physics integration tool. Advances in Engineering Software 60-61:89 - 97, 2013. DOI:10.1016/j.advengsoft.2012.09.005

[6] The European Materials Modelling Council - MODA, homepage. URL: https://emmc.info/moda/.

[7] U. Wickström, D. Duthinh, K. McGrattan. Adiabatic surface temperature for calculating heat transfer to fire exposed structures. In Proceedings of the Eleventh International Interflam Conferrence. Inter Science Communications Limited, London, 2007.

[8] EN 1991-1-2: Eurocode 1: Actions on structures - part 1-2: General actions - actions on structures exposed to fire, 2002.

[9] EN 1363-1 fire resistance tests - part 1: General requirements, 2012. 